\title{
Durability of Fly Ash Cement Concrete Pavement in Cold Areas
}

\author{
Mandula \\ Transportation Institute, Inner Mongolia University, Hohhot, China \\ 1592673507@qq.com
}

Key words: Fly ash concrete roads, Flexural strength, Freezing and thawing, Abrasion resistance Abstract: Based on the freeze-thawing cycle characteristic of road concrete in cold climatic condition. The objective of this paper was to estimate the practicality of using fly ash discharged from a coal fuel electric plant in Inner Mongolia in concrete pavements. The abrasion resistance of road concrete containing fly ash was studied after suffering freeze-thawing cycles. The results indicate that the coarse aggregates were exposed after freeze-thawing cycle test and the replacement ratio of fly ash has little influence on the abrasion resistance.

\section{Introduction}

With the rapid development of Chinese economy, our country increases constructions of the road fundamental establishment constantly in rural and pastoral areas, so lead to the shortage of road constructional materials. Thus, developing the new road materials which suit to each grade road and climatic conditions has a positive affect in the road traffic development. Besides, with the development of China electric, the discharge quantities of fly ash are growing rapidly so as to cause serious environmental pollution. Scientific utilization of fly ash has profound significances for saving resources and protecting environment[1,2]. Based on the pavement surface course in northern China suffering freeze-thawing cycle and abrasion action as well as some experimental results, by laboratory experiments, this paper discuss the pavement performance of fly ash.

\section{Experimental designs}

\section{Experimental material}

Fly ash

The fly ash comes from a coal fuel electric plant in Inner Mongolia. The main component of fly ash are shown in Table1. The humidity, ignition loss (JIS A 6201-1999), density, specific surface area, activity-index (JIS A 6201) of fly ash were also measured.

Aggregate

Crushed stone and mountain sand are used as aggregate in this test, maximal size of coarse aggregate is $20 \mathrm{~mm}$. Some properties of aggregate are shown in Table2.

Table1 Main component of fly ash (\%)

\begin{tabular}{|c|c|c|c|c|c|}
\hline $\mathrm{Name}^{\text {Items }}$ & $\mathrm{SiO}_{2}$ & $\mathrm{Al}_{2} \mathrm{O}_{3}$ & $\mathrm{Fe}_{2} \mathrm{O}_{3}$ & $\mathrm{CaO}$ & LOI \\
\hline Fly ash & 68.9 & 13.2 & 8.1 & 4.5 & 0.3 \\
\hline
\end{tabular}

Table2 Properties of aggregate

\begin{tabular}{c|c|c|c}
\hline Names & $\begin{array}{c}\text { Density } \\
\left(\mathrm{g} / \mathrm{cm}^{3}\right)\end{array}$ & $\begin{array}{c}\text { Water } \\
\text { absorption }\end{array}$ & $\mathrm{Mx}$ \\
\hline Fine aggregate & 2.59 & 1.59 & 1.84 \\
\hline Coarse aggregate & 2.6 & 1.62 & - \\
\hline
\end{tabular}




\section{Test content}

The method of freeze-thawing test used freeze-thawing test in water according to JIS A 1148-2001[3]. The abrasion test used BBM testing machine based on the US ASTM C/779/C 《Standard Test Method for Abrasion Resistance of Horizontal Concrete Surfaces》[4,5]. The number of specimens used for flexural strength test is three. The height of specimen is $100 \mathrm{~mm}$, the width is $100 \mathrm{~mm}$ and the length is $400 \mathrm{~mm}$. The number of specimens used for abrasion test after freeze-thawing test is three. The specimens use the same sizes as above. Besides, in order to analysis the impacts of freeze-thawing cycle on abrasion resistance, contrast tests were conducted using same mixing ratio. Table 3 shows the mixture ratio of concrete. The target slump is $2.5 \mathrm{~cm}$ and water-binder ratio is $45 \%$. Using ordinary Portland cement, high performance AE water-reducer and $20^{\circ} \mathrm{C}$ tap water. The replacement ratio of fly ash are $0 \%, 30 \%$ and $50 \%$ separately(F0,F3,F5).

After formed, letting the specimens sit for $1 \mathrm{~d}$ at $20^{\circ} \mathrm{C} \pm 5^{\circ} \mathrm{C}$, then conducting standard curing in $20^{\circ}$ Cconstant temperature tank. The number of freeze-thawing cycle is 300 , each freeze-thawing cycle time is $3 \sim 4$ hours. The mass, ultrasonic propagation time, dynamic modulus of elasticity and mass reduction ratio must be measured every 6 cycles. The loading force of abrasion machine is $115 \mathrm{~N}$, the rotate speed is $90 \mathrm{rpm}$, the abrasion time is $20 \mathrm{~min}$ and the steel ball diameter is $200 \mathrm{~mm}$. Measuring the depth of the four points on the track of abrasion every $5 \mathrm{~min}$ then taking the average as the abrasion value.

Table3 Mixture ratio of concrete

\begin{tabular}{|c|c|c|c|c|c|c|c|c|}
\hline \multirow[b]{2}{*}{ Number } & \multirow[b]{2}{*}{$\begin{array}{c}\text { water-binder } \\
\text { ratio }(\%)\end{array}$} & \multirow[b]{2}{*}{$\begin{array}{c}\text { Sand } \\
\operatorname{ratio}(\%)\end{array}$} & \multicolumn{6}{|c|}{ Material content $\left(\mathrm{kg} / \mathrm{m}^{3}\right)$} \\
\hline & & & $\begin{array}{l}\text { water } \\
\text { W }\end{array}$ & $\begin{array}{c}\text { Cement } \\
\text { C }\end{array}$ & $\begin{array}{c}\text { Fly ash } \\
\text { F }\end{array}$ & $\begin{array}{c}\text { Fine } \\
\text { aggregate } \\
\text { S } \\
\end{array}$ & $\begin{array}{c}\text { Coarse } \\
\text { aggrete } \\
\text { G }\end{array}$ & $\begin{array}{c}\mathrm{AE} \\
\text { water-reducer }\end{array}$ \\
\hline F0 & 45 & 39 & 144 & 320 & 0 & 722 & 1133 & 1.92 \\
\hline F3 & 45 & 38 & 144 & 224 & 96 & 705 & 1133 & 2.88 \\
\hline F5 & 45 & 37 & 144 & 160 & 160 & 653 & 1133 & 3.32 \\
\hline
\end{tabular}

\section{Experimental results and analyses}

\section{The density and flexural strength}

The density and flexural strength of fly ash concrete are shown in Fig.1 and Fig.2. Besides, as shown in Fig3, the relationships of age to flexural strength are expressed with the flexural strength ratio, that is the ratio of the flexural strength of each age to $28 \mathrm{~d}$. Because of the density of fly ash is less than the ordinary Portland cement, so the density of fly-ash concrete decreases with the raising of replacement ratio $(\mathrm{F} 5<\mathrm{F} 3<\mathrm{F} 0)$.

The flexural strength is the main mechanical property control index of pavement cement concrete. From Fig.2 and Fig.3 we can see the flexural strength decreases with the raising of replacement ratio, the fly-ash concrete's growth rates of flexural strength are greater than F0 with age, when age is $91 \mathrm{~d}$, the flexural strength of F3 is close to F0, when age is $28 \mathrm{~d}$, F5 can meet the minimum design requirements of pavement concrete. 


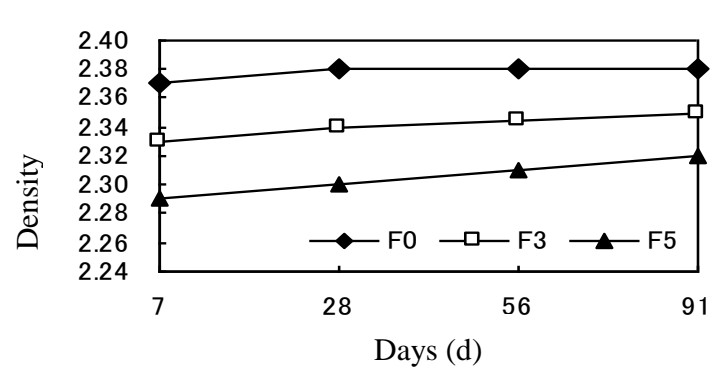

Fig.1 The relationships of density to replacement ratio

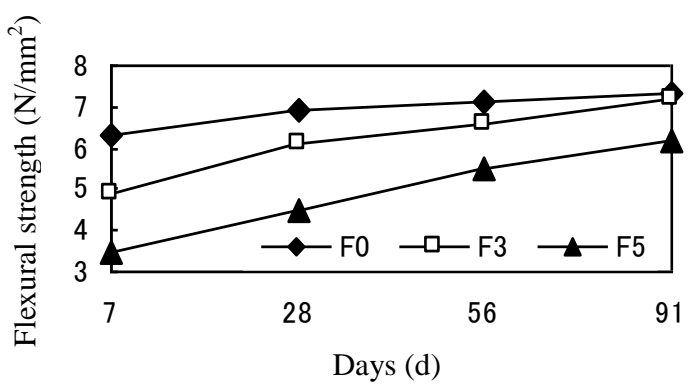

Fig.2 The relationships of flexural strength to replacement ratio

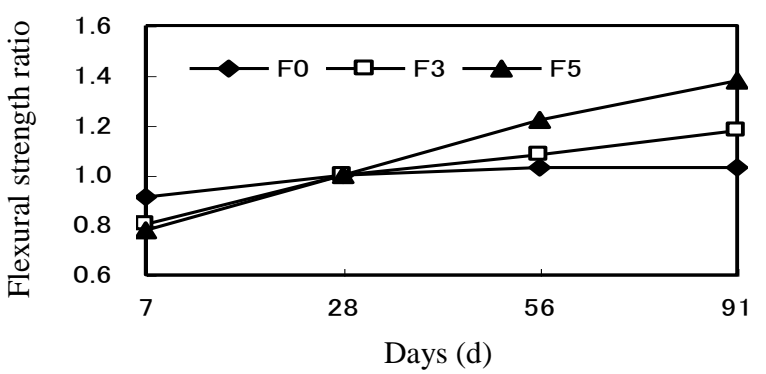

Fig.3 The flexural strength ratio at each ages

\section{The frost resistant properties}

The measure results of ultrasonic speed are shown in Fig.4. We can find that the speed of ultrasonic decreases with the raising of replacement ratio. All specimen' measured values are greater than $4000 \mathrm{~m} / \mathrm{s}$ and can be kept until 300 cycles. So the negative impact of freeze-thawing cycle action on specimen is relatively small.

After 300cycles, roughly the same phenomena of spalling were found on the surface of specimens. The speed of ultrasonic and relative dynamic modulus of elasticity decreased with the raising of cycle numbers. There aren't big degradation phenomenon occur in the internal structure of specimens according to ultrasonic speed and relative dynamic modulus of elasticity.

\section{The attrition resistance}

The concrete strength increases with the raising of age, furthermore, the strength and the attrition resistance have the good positive correlation[6,7].In this test, the wear depth at the age of 91d are relatively smaller than $28 \mathrm{~d}$, but the growth rate of abrasion decreases slowly with the raising of wearing time. This is due to the thin mortar layer on the surface of specimens has gradually been worn and coarse aggregate been exposed on specimens surface, the attrition resistance of coarse aggregate normally is better than mortar.

The wear depth increases with the raising of replacement ratio of fly-ash. The wear depth difference between F3 and F5 is $0.6 \mathrm{~mm}$ when the age is $28 \mathrm{~d}$ and wearing time is $20 \mathrm{~min}$. The wear depth of F5 is 1.7 times of F0, F3 is 1.4 times of F4 at the age of $28 \mathrm{~d}$ and wearing time is $20 \mathrm{~min}$. The wear depth of F5 is 1.3 times of F0, F3 and F0 have roughly equal wear depth. All of this indicates that the replacement ratio of fly-ash has little impact on the growth rate of wear depth. 


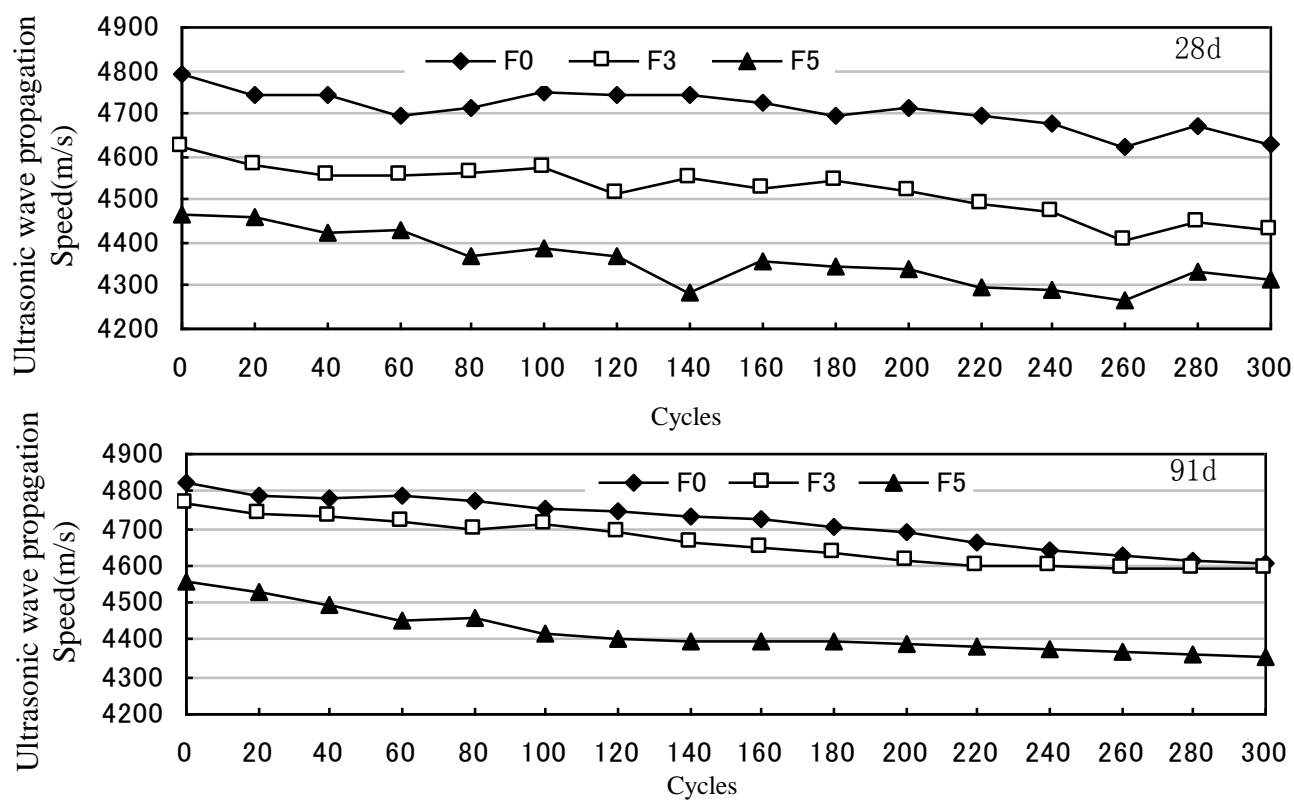

Fig.4 Pulse velocity ratings of specimens for freezing and thawing test

Fig.5 shows the specimens' flexural strength after suffering freeze-thawing cycle action. When age is $28 \mathrm{~d}$, the flexural strength of F0, F3 and F5 is $6.7,6.1$ and $4.4 \mathrm{~N} / \mathrm{mm}^{2}$ respectively, when age is $91 \mathrm{~d}$, the flexural strength of F0, F3 and F5 is 7.2, 7.1 and $6.0 \mathrm{~N} / \mathrm{mm}^{2}$ respectively. The difference is not large compared to those specimens that having same mix proportion and age but without suffering freeze-thawing cycle.

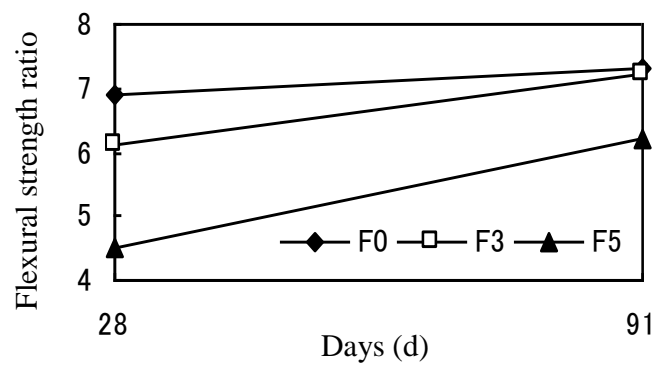

T Fig.5 The flexural strength after freeze-thawing cycle action

\section{Conclusion}

Through lots of laboratory tests, the frost resistant properties of fly-ash pavement concrete and the attrition resistance of fly-ash pavement concrete that suffering and not suffering freeze-thawing cycle were analyzed in this paper. A few conclusions are obtained:

(1) When age is $28 \mathrm{~d}$, using fly-ash coming form a coal fuel electric plant in Inner Mongolia to replace $50 \%$ ordinary Portland cement can meet the light traffic volume flexural strength requirements of pavement concrete $\left(4.0 \mathrm{~N} / \mathrm{mm}^{2}\right)$.

(2) The fly-ash pavement concrete's surface mortar will be peeled after suffering freeze-thawing cycle action but those actions have little influence on specimen's internal structure according to ultrasonic speed and relative dynamic modulus of elasticity. 
(3) Due to the surface mortar is peeled after freeze-thawing cycle action, the coarse aggregate exposed can resist the action of abrasion and the wear energy per unit of area decreases slowly, the replacement ratio of fly-ash has little impact on the attrition resistance of concrete.

(4) When the design age is 91d, the attrition resistance increases obviously and the wear depth decreases markedly. So the characteristics of the intensity development of fly-ash concrete should be considered. Just make sure the strength development of fly-ash, the attrition resistance and frost resistant properties of concrete can be ensured.

(5) According to the test results, this paper proving the possibility of using fly-ash in concrete materials in rural and pastoral areas of northern China when the replacement ratio of fly-ash within $50 \%$.

\section{Acknowledgements}

The authors would like to acknowledge the finacial supported by the Nationnal Natural Science Foundation of China(51568052)

\section{References}

[1] Information on to http://www.sdpc.gov.cn/hjbh/hjjsjyxsh/t20090525281355.htm

[2] MAO Shendong, LI Zhen, FANG Ying: Journal of Concrete, in Chinese (2011)

[3] Japanese Industrial Standards Committee: Japan's National Institute of Standards/Asahi Press, Tokyo(2001)

[4] Mandula, HATTORI Kunio, OGATA Hidehiko,NATSUKA Isamu and GUO Shiwen: The Japanese Society of Irrigation, Drainage and Rural Engineering (2009)

[5] Shanghai Institute of Standardization translation:American Society of TestingMaterials/ Sta ndards Press of China,Beijing (2003)

[6] OGATA Hidehiko, SATO Shushi, Masayuki Ishii,Takada Ryuichi: Journal of Concrete Research and technology, in Japanese(2005)

[7] Mandula, HATTORI Kunio, OGATA Hidehiko, GUO Shiwen, GOYAL AJAY, ANWAR A M:Highlights of Sciencepaper Online, in Chinese. (2009) 